\title{
Delayed emesis: moderately emetogenic chemotherapy (single-day chemotherapy regimens only)
}

\author{
Fausto Roila • David Warr • Matti Aapro • Rebecca A. Clark-Snow • Larry Einhorn • \\ Richard J. Gralla • Jorn Herrstedt • Mitsue Saito • Maurizio Tonato
}

Received: 2 August 2010 / Accepted: 1 November 2010/Published online: 5 December 2010

(C) Springer-Verlag 2010

\begin{abstract}
Purpose An update of the recommendations for the prophylaxis of delayed emesis induced by moderately emetogenic chemotherapy discussed during the third Perugia Consensus Conference (June 2009) sponsored by MASCC-ESMO was presented. The review considered new studies published since the second consensus conference (April 2004).

Methods An online search was used conducting PubMed and the search terms moderately, chemotherapy, and emesis with a restriction to papers in English.

Results Overall, nine randomized controlled studies were included: four evaluating NK1 receptor antagonists, one palonosetron, and four dopamine receptor antagonists.

Conclusions In patients receiving a combination of anthracycline plus cyclophosphamide treated with a combination of aprepitant, a $5-\mathrm{HT}_{3}$ receptor antagonist and dexamethasone to prevent acute nausea and vomiting, aprepitant is suggested
\end{abstract}

F. Roila $(\bowtie)$

S. Maria Hospital,

Terni, Italy

e-mail: roila.fausto@libero.it

D. Warr

Princess Margaret Hospital, University of Toronto,

Toronto, Canada

M. Aapro

Clinique de Genolier,

Genolier, Switzerland

R. A. Clark-Snow

University of Kansas Cancer Center,

Kansas City, KS, USA

L. Einhorn

Walther Cancer Institute,

Indianapolis, IN, USA to prevent delayed emesis. In patients who do not receive aprepitant for the prophylaxis for acute emesis and in which palonosetron is recommended, a multiday oral dexamethasone is the preferred treatment for the prevention of delayed emesis. Levels of evidence and of consensus for both recommendations are moderate.

Keywords Moderately emetogenic chemotherapy · Delayed emesis · Neurokinin antagonists · Serotonin antagonists .

Dopamine receptor antagonists

The risk of delayed emesis has been well studied in patients who have received a combination of an anthracycline and cyclophosphamide but is less clear for other agents classified as moderately emetogenic. The major prognostic factor of the frequency of delayed onset nausea and vomiting is the occurrence of acute-onset emesis. Therefore,

R. J. Gralla

New York Lung Cancer Alliance,

New York, NY, USA

J. Herrstedt

Odense University Hospital,

Odense, Denmark

M. Saito

Department of Breast Oncology, Juntendo University Hospital, Hongo 3-1-3, Bunkyo-ky,

Tokyo, Japan 113-8431

M. Tonato

Regional Cancer Centre,

Perugia, Italy 
emphasis should be placed upon the control of emesis in the first $24 \mathrm{~h}$. There are, however, randomized clinical studies that show the efficacy of some antiemetic drugs specifically against delayed emesis.

Table 1 shows the current Multinational Association of Supportive Care in Cancer (MASCC), American Society of Clinical Oncology (ASCO), American Society of HealthSystem Pharmacists (ASHP), European Society for Medical Oncology (ESMO), and National Comprehensive Cancer Network (NCCN) practice guidelines for prophylaxis of delayed emesis following moderately emetogenic chemotherapy [1-5]. The recommendations range from routine use of aprepitant, corticosteroids, 5-hydroxytryptamine $\left(5-\mathrm{HT}_{3}\right)$ antagonists in combination to the use of these agents only when the physician feels that the risk is high enough to warrant prophylaxis. This diversity of recommendations reflects the limited high quality of evidence and the lack of a precise definition of those groups who are at substantial risk for delayed nausea and emesis. In addition, the ASHP guidelines were published 7-10 years prior to any of the other guidelines and before any neurokinin 1 $\left(\mathrm{NK}_{1}\right)$ receptor antagonist was commercially available.

Antiemetic studies that report results in the delayed phase of emesis are of two types: those in which the antiemetic therapies differ only beyond day 1 and those in which there is a difference starting at day 1 [6]. The latter studies are problematic to interpret when there is a difference in the control of emesis in the acute phase because the strongest prognostic factor for delayed emesis is the occurrence of nausea or emesis in the acute phase. None of the studies reviewed carried out a statistical analysis that adjusted for the differences in antiemetic control in the acute phase. Thus, studies in which antiemetic efficacy differs between the randomized groups in the acute phase can describe the frequency with which nausea and vomiting occur in the delayed phase but cannot distinguish an effect due to administration in the delayed phase from an effect due to better antiemetic control in the first $24 \mathrm{~h}$.

The following is a summary of the evidence available at the time of the Perugia International Antiemetic Consensus Conference in 2004 with respect to delayed emesis in moderately emetogenic chemotherapy [6]:

\section{Corticosteroids}

Two out of three randomized trials have shown that administration of dexamethasone $4 \mathrm{mg}$ bid on days 2 to 5 reduces the likelihood of delayed-onset emesis with the third study being underpowered to detect clinically important differences.

\section{5-Hydroxytryptamine receptor antagonists}

Four studies showed a trend for better control of delayed vomiting in the patients who received a $5-\mathrm{HT}_{3}$ receptor antagonist beyond day 1 , but only one showed a statistically significant difference. Two studies of palonosetron showed efficacy that was superior to a single intravenous administration of dolasetron or ondansetron in both the acute and delayed phases. The superiority in the initial $24 \mathrm{~h}$ could explain much of the superiority observed in the delayed phase. Less than $5 \%$ of patients received corticosteroids combined with $5-\mathrm{HT}_{3}$ receptor antagonists and hence did not receive what is considered to be standard therapy. For that reason, guideline groups did not feel that the evidence was sufficient to endorse palonosetron
Table 1 Current Consensus Guideline Recommendations

\begin{tabular}{|c|c|c|}
\hline Group & Comment & Options beyond day 1 \\
\hline \multirow[t]{2}{*}{ MASCC [1] } & $\begin{array}{l}\text { Anthracycline }+ \\
\text { cyclophosphamide (AC) }\end{array}$ & Aprepitant or dexamethasone \\
\hline & Moderate other than AC & $\begin{array}{l}\text { Dexamethasone or a } \\
5-\mathrm{HT}_{3} \text { antagonist }\end{array}$ \\
\hline \multirow[t]{2}{*}{ ASCO [2] } & $\begin{array}{l}\text { Anthracycline }+ \\
\text { cyclophosphamide (AC) }\end{array}$ & Aprepitant \\
\hline & Moderate other than AC & $\begin{array}{l}\text { Dexamethasone or a } \\
5-\mathrm{HT}_{3} \text { antagonist }\end{array}$ \\
\hline ASHP [3] & All moderately emetogenic & $\begin{array}{l}\text { 5- } \mathrm{HT}_{3} \text { antagonist plus } \\
\text { dexamethasone }\end{array}$ \\
\hline \multirow[t]{2}{*}{ ESMO [4] } & $\begin{array}{l}\text { Anthracycline }+ \\
\text { cyclophosphamide (AC) }\end{array}$ & Aprepitant or dexamethasone \\
\hline & Moderate other than $\mathrm{AC}$ & Corticosteroid or a $5-\mathrm{HT}_{3}$ antagonist \\
\hline \multirow[t]{3}{*}{ NCCN [5] } & All moderately emetogenic & Aprepitant \pm dexamethasone OR \\
\hline & & Dexamethasone OR \\
\hline & & $\begin{array}{l}5-\mathrm{HT}_{3} \text { antagonist } \pm \text { lorazepam } \pm \mathrm{H} 2 \\
\text { blocker or proton pump inhibitor }\end{array}$ \\
\hline
\end{tabular}


as the $5-\mathrm{HT}_{3}$ receptor antagonist of choice for preventing delayed emesis.

\section{Dopamine receptor antagonists}

Two studies provide weak evidence that the addition of a dopamine receptor antagonist may improve the control of delayed-onset nausea.

\section{Neurokinin $(\mathbf{N K})_{1}$ receptor antagonists}

No studies were reported.

\section{Update of literature}

An online search was used conducting PubMed and the search terms moderately, chemotherapy, and emesis with a restriction to papers in English from 2004 onward. In addition, a search was done of the terms casopitant, aprepitant, granisetron, ondansetron, dolasetron, tropisetron, or palonosetron along with emesis, restricting the search to randomized trials. Abstracts were reviewed. Studies were included only if the subjects received moderately emetogenic chemotherapy as defined by MASCC. A paper that included both high and moderate semetogenicity was considered acceptable if there was a separate analysis of the moderately emetogenic group. Open-label or crossover design studies were reviewed but accepted only as supportive evidence or hypothesis-generating evidence.

\section{$\mathrm{NK}_{1}$ receptor antagonists}

Following the 2004 Perugia Consensus Conference, four studies have been reported in which $\mathrm{NK}_{1}$ receptor antagonists were used in patients receiving moderately emetogenic chemotherapy. All studies were double-blinded and three included only subjects who received an anthracycline and cyclophosphamide (AC)-based chemotherapy regimen for breast cancer. The fourth study enrolled patients scheduled to receive a single dose of at least one moderately emetogenic chemotherapy agent. All three studies with aprepitant had the same standard therapy and experimental antiemetic therapy. The study with casopitant differed slightly in design in that ondansetron was given for 3 days in both the standard and experimental groups whereas in aprepitant studies, ondansetron was continued beyond day 1 only in the standard therapy group.

In the first study, 866 patients treated with cyclophosphamide \pm doxorubicin or epirubicin were randomized to receive oral aprepitant $125 \mathrm{mg}$ on day 1 and $80 \mathrm{mg}$ on days 2 and 3 combined with oral ondansetron $8 \mathrm{mg}$ bid on day 1 only and oral dexamethasone $12 \mathrm{mg}$ before chemotherapy or oral ondansetron $8 \mathrm{mg}$ bid on days 1-3 and oral dexamethasone $20 \mathrm{mg}$ before chemotherapy [7]. The complete response (definite as no emesis and no need for rescue medication) rate from days $1-5$ as well as from day 1 was significantly superior $(51 \%$ versus $42 \%$ and $76 \%$ versus $69 \%$, respectively) with the aprepitant combination. Numerical (but not statistical) superiority was observed on days 2-4 (55\% versus $49 \%)$. Although there was an absolute $17 \%$ reduction in the proportion of patients with emesis, there was no detectable effect on nausea. The results of this study led to the introduction of aprepitant in the update of the MASCC antiemetics recommendations (see Table 1).

In a much smaller study, 127 patients were randomized to the same standard and experimental therapy as in reference 7 [8]. There was a nonsignificant trend in favor of aprepitant in the primary outcome of complete response from $0-120 \mathrm{~h}(46.8 \%$ vs $41.9 \%)$ and in delayed phase $(64.4 \%$ vs $57.8 \%)$. This study was inadequately powered in that it was designed to have an $80 \%$ chance of detecting a $25 \%$ difference in the complete response rate.

A third study of the same design was carried out in 848 patients who received one or more of the following different moderately emetogenic chemotherapy agents: oxaliplatin, carboplatin, epirubicin, idarubicin, ifosfamide, irinotecan, daunorubicin, doxorubicin, cyclophosphamide $\left(<1,500 \mathrm{mg} / \mathrm{m}^{2}\right)$, or cytarabine $\left(>1 \mathrm{~g} / \mathrm{m}^{2}\right)$ [9]. An anthracycline + cyclophosphamide regimen was administered in $48 \%$ of patients. No vomiting (the primary endpoint) was significantly superior with the addition of aprepitant regardless of whether patients received $\mathrm{AC}$ or non-AC regimens $(76.2 \%$ vs $62.1 \%$ on days $1-5,92.0 \%$ vs $83.7 \%$ on day 1 , and $77.9 \%$ vs $66.8 \%$ on days $2-5$. This is the only study to date that has incorporated non-AC chemotherapy. The lack of information about the distribution and dose of the non-AC chemotherapy in each arm means that it is not possible to be sure that there were no important imbalances in the emetogenicity. It should also be noted that the analysis according to type of chemotherapy (AC vs non-AC) was post hoc.

A study of similar but not identical design was carried out using the $\mathrm{NK}_{1}$ receptor antagonist, casopitant, in patients receiving AC [10]. All patients received dexamethasone $8 \mathrm{mg}$ iv on day 1 and oral ondansetron $8 \mathrm{mg}$ twice daily on days $1-3$. Patients were randomized to a single oral dose of casopitant (150 mg on day 1), a 3-day oral casopitant arm (150 mgday $1+50 \mathrm{mg}$ days $2-3)$, a 3-day iv/ oral casopitant arm $(90 \mathrm{mg}$ iv on day 1 and $50 \mathrm{mg}$ orally on days 2-3), or a control arm. Complete response on days 1-5 was significantly superior with casopitant $(73 \%, 73 \%$, and 
$74 \%$, respectively) than with the control arm (59\%). In these patients, the complete response on day 1 was similar $(88 \%$, $89 \%, 86 \%$, and $85 \%$, respectively) while on days $2-5$, it was numerically, but not statistically, superior with casopitant $(73 \%, 73 \%, 74 \%$, and $59 \%)$. As with the adequately powered aprepitant study, there was a large reduction in the number of patients with emesis but no effect upon nausea.

Summary The adequately powered studies of aprepitant and casopitant demonstrate that when added to a $5-\mathrm{HT}_{3}$ receptor antagonist and dexamethasone, an $\mathrm{NK}_{1}$ receptor antagonist reduces the incidence of acute and delayed emesis induced by anthracycline and cyclophosphamidebased chemotherapy. At present, the evidence is insufficient to recommend routine administration of an NK1 receptor antagonist for other moderately emetogenic chemotherapy. These studies have not addressed the issue of whether an $\mathrm{NK}_{1}$ receptor antagonist needs to be administered beyond day 1 in order to improve emesis in the delayed phase. Since dexamethasone was not administered beyond $24 \mathrm{~h}$, the importance of a corticosteroid in the delayed phase when an $\mathrm{NK}_{1}$ receptor antagonist is given is not known.

\section{Palonosetron}

Recently, the combination of palonosetron $(0.75 \mathrm{mg}$ iv) plus dexamethasone (16 $\mathrm{mg}$ iv) has been compared with granisetron $(40 \mu \mathrm{g} / \mathrm{kg}$ iv) plus dexamethasone in a double-blind, randomized study involving 1,114 cancer patients who received cisplatin (57\%) or AC/epirubicin and cyclophosphamide (EC) (43\%) chemotherapeutic regimens [11]. All patients received dexamethasone $8 \mathrm{mg}$ iv on days 2 and 3 if treated with cisplatin and $4 \mathrm{mg}$ orally if treated with $\mathrm{AC} /$ EC. During the acute phase, a similar complete response was achieved (75.3\% versus $73.3 \%$, respectively). During the delayed phase, $56.8 \%$ of patients had a complete response in the palonosetron group compared with $44.5 \%$ in the granisetron group $(p<0.0001)$. Despite some shortcomings of the study (i.e., cisplatin- and non-cisplatintreated patients were combined and doses of dexamethasone lower than those recommended for acute and delayed emesis prophylaxis), the similar results achieved in the first $24 \mathrm{~h}$ permit us to conclude that palonosetron provided more protection from delayed emesis than a single administration before chemotherapy of granisetron. This study does not address the issue of whether palonosetron is superior to other $5-\mathrm{HT}_{3}$ receptor antagonists when an $\mathrm{NK}_{1}$ receptor antagonist is used as recommended by guidelines. The demonstration of superiority only in the delayed phase raises the question of whether administra- tion of the granisetron for more than $24 \mathrm{~h}$ would have achieved equivalent results to palonosetron.

Summary This study provides strong evidence that, in patients who receive moderately emetogenic chemotherapy, one dose of palonosetron, administered before chemotherapy, is more efficacious in reducing the incidence of delayed emesis than a single dose of a $5-\mathrm{HT}_{3}$ receptor antagonist with a shorter half-life.

\section{Dopamine receptor antagonists}

Four studies have been published [12-15]. In one, 691 untreated patients treated with doxorubicin-containing chemotherapy plus a $5-\mathrm{HT}_{3}$ receptor antagonist plus dexamethasone to prevent acute emesis were randomized to receive oral prochlorperazine $10 \mathrm{mg}$ tid on days 2 and 3 , or an oral $5-\mathrm{HT}_{3}$ receptor antagonist (ondansetron, granisetron, or dolasetron), or $10 \mathrm{mg}$ of prochlorperazine taken as needed [12]. The primary endpoint was mean severity of delayed nausea. No difference in mean severity of nausea was observed. A major limitation of this study is that it was not double-blind.

In the second study, 232 patients who received moderately high to highly emetogenic chemotherapy and treated with ondansetron plus dexamethasone to prevent acute emesis were randomized to receive on days $2-515 \mathrm{mg}$ of prochlorperazine spansules twice daily, or $8 \mathrm{mg}$ of ondansetron tablets twice daily, or $8 \mathrm{mg}$ of dexamethasone tablets twice daily [13]. This was not a double-blind study. No differences were observed between the three antiemetic treatments. The absence of superiority of the dexamethasone arm is surprising, given the results from other studies of moderately and highly emetogenic chemotherapy. This raises the question of whether there is true equivalence among the treatments or if the study, due to chance, poor compliance, or some lack of sensitivity of the methodology, simply failed to detect a true difference in efficacy.

In the third study, an open-label crossover study, 99 pretreated and chemotherapy-naive patients receiving different moderately emetogenic chemotherapy were randomized to receive sublingual metopimazine $(15 \mathrm{mg}$ tid) or ondansetron $8 \mathrm{mg}$ bid for 5 days[14]. All patients received $48 \mathrm{mg}$ of oral methylprednisolone. Treatment was successful (no vomiting and less than two episodes of nausea) in preventing delayed emesis in $73.6 \%$ during treatment with metopimazine and in $57.5 \%$, during ondansetron. Constipation was significantly more common in those who received ondansetron. Unfortunately, it was not a blind study, and no information on the results achieved on day 1 in the two groups of patients was reported. 
In the fourth study which was double-blind, 200 untreated and previously chemotherapy-treated patients receiving different moderately emetogenic chemotherapy were randomized to sublingual metopimazine $15 \mathrm{mg}$ tid or sublingual ondansetron $8 \mathrm{mg}$ bid for 5 days [15]. No differences were shown in complete response $(53.4 \%$ vs $49.5 \%)$ or in the incidence of emesis $(23.3 \%$ vs $30.9 \%$, respectively). Gastrointestinal disorders (constipation and abdominal pain) were more frequent with ondansetron. The major limitations of this study were that treatment for preventing acute emesis was left to each investigator's discretion, and that results achieved on day 1 for the two groups of patients were not reported.

Summary The results of these studies do not modify the previous recommendation of a weak evidence that a dopamine receptor antagonist may improve the control of delayed emesis.

\section{Conclusions}

Patients who receive moderately emetogenic chemotherapy known to be associated with a significant incidence of delayed nausea and vomiting should receive antiemetic prophylaxis for delayed emesis.

MASCC level of confidence: high; level of consensus: high

ESMO level of evidence: I; grade of recommendation: A

In breast cancer patients receiving a combination of anthracycline plus cyclophosphamide treated with a combination of aprepitant, a 5- $\mathrm{HT}_{3}$ receptor antagonist and dexamethasone to prevent acute nausea and vomiting, aprepitant should be used to prevent delayed nausea and vomiting.

MASCC level of confidence: moderate; level of consensus: moderate

ESMO level of evidence: II; grade of recommendation: B

In patients receiving chemotherapy of moderate emetic risk which does not include a combination of anthracycline plus cyclophosphamide and in which palonosetron is recommended for the prophylaxis of acute emesis, multiday oral dexamethasone treatment is the preferred treatment for the prevention of delayed emesis.

MASCC level of confidence: moderate; level of consensus: moderate

ESMO level of evidence: II; grade of recommendation: B

The optimal duration and dose of dexamethasone have not been defined.

Further studies are required to clarify the role of more widely available dopamine receptor antagonists such as metoclopramide, prochlorperazine, or domperidone.
Acknowledgement The 2009 MASCC/ESMO Antiemetic Guideline Update Consensus Meeting was funded by unrestricted grants from Eisai Inc, GlaxoSmithKline, Helsinn Healthcare SA, Merck \& Co. Inc., and Prostrakan Group. These sources had no role in the design, conduct, or results of the conference nor in the preparation of data or this manuscript. Additionally, funding was received from the European Society of Medical Oncology (ESMO) and the Multinational Association of Supportive Care in Cancer (MASCC). MASCC organized the meeting. Individual members of either or both these organizations participated in the meeting and preparation of the manuscript.

Conflict of interest statement The following authors either received research funding, honoraria, or have been a consultant to or an expert witness for:Roila: GSK, Helsinn, Merck; Warr: GSK. Merck; Aapro: GSK, Helsinn, Merck, Eisai, ProStrakan; Clark-Snow: No conflicts reported; Gralla: GSK, Helsinn, Merck, Eisai; Herrstedt: GSK, Helsinn, Merck; Saito: No conflicts reported; Tonato: No conflicts reported; Einhorn (wife) has been an investor in GSK

\section{References}

1. Roila F, Hesketh PJ, Herrstedt J (2006) Prevention of chemotherapy- and radiotherapy-induced emesis: results of the 2004 Perugia International Antiemetic Consensus Conference. Ann Oncol 17(1):20-28

2. Kris MG, Hesketh PJ, Somerfield MR, Feyer P, Clark-Snow R, Koeller $\mathrm{JM}$ et al (2006) American Society of Clinical Oncology guideline for antiemetics in oncology: update 2006. J Clin Oncol 24(18):2932-2947

3. ASHP (1999) Therapeutic guidelines on the pharmacologic management of nausea and vomiting in adult and pediatric patients receiving chemotherapy or radiation therapy or undergoing surgery. Am J Health Syst Pharm 56(8):729-764

4. Herrstedt J, Roila F (2009) Chemotherapy-induced nausea and vomiting: ESMO clinical recommendations for prophylaxis. Ann Oncol 20(Suppl 4):156-158

5. NCCN practice guidelines in oncology: antiemesis V.3.2009

6. Roila F, Warr D, Clark-Snow RA, Tonato M, Gralla RJ, Einhorn LH et al (2005) Delayed emesis: moderately emetogenic chemotherapy. Support Care Cancer 13(2):104-108

7. Warr DG, Hesketh PJ, Gralla RJ, Muss HB, Herrstedt J, Eisenberg PD et al (2005) Efficacy and tolerability of aprepitant for the prevention of chemotherapy-induced nausea and vomiting in patients with breast cancer after moderately emetogenic chemotherapy. J Clin Oncol 23(12):2822-2830

8. Yeo W, Mo FK, Suen JJ, Ho WM, Chan SL, Lau W et al (2009) A randomized study of aprepitant, ondansetron and dexamethasone for chemotherapy-induced nausea and vomiting in Chinese breast cancer patients receiving moderately emetogenic chemotherapy. Breast Cancer Res Treat 113(3):529-535

9. Rapoport BL, Jordan K (2010) Aprepitant for the prevention of chemotherapy-induced nausea and vomiting associated with a broad range of moderately emetogenic chemotherapies and tumor types: a randomized, double-blind study. Support Care Cancer 188 (4):423-431

10. Herrstedt J, Apornwirat W, Shaharyar A, Aziz Z, Roila F, Van Belle S et al (2009) Phase III trial of casopitant, a novel neurokinin-1 receptor antagonist, for the prevention of nausea and vomiting in patients receiving moderately emetogenic chemotherapy. J Clin Oncol 27(32):5363-5369

11. Saito M, Aogi K, Sekine I, Yoshizawa H, Yanagita Y, Sakai H et al (2009) Palonosetron plus dexamethasone versus granisetron plus dexamethasone for prevention of nausea and vomiting during chemotherapy: a double-blind, double-dummy, randomised, comparative phase III trial. Lancet Oncol 10(2):115-124 
12. Hickok JT, Roscoe JA, Morrow GR, Bole CW, Zhao H, Hoelzer KL et al (2005) 5-Hydroxytryptamine-receptor antagonists versus prochlorperazine for control of delayed nausea caused by doxorubicin: a URCC CCOP randomised controlled trial. Lancet Oncol 6(10):765-772

13. Lindley C, Goodin S, McCune J, Kane M, Amamoo MA, Shord S et al (2005) Prevention of delayed chemotherapy-induced nausea and vomiting after moderately high to highly emetogenic chemotherapy: comparison of ondansetron, prochlorperazine, and dexamethasone. Am J Clin Oncol 28(3):270-276
14. Bloch J, Rixe O, Meric JB, Delgado A, Khayat D (2005) Comparison of the efficacy and safety of combinations of metopimazine or ondansetron with methylprednisolone in the prevention of delayed emesis in patients receiving chemotherapy. Curr Med Res Opin 21(11):1763-1771

15. Khamales S, Bethune-Volters A, Chidiac J, Bensaoula O, Delgado A, Di Palma M (2006) A randomized, double-blind trial assessing the efficacy and safety of sublingual metopimazine and ondansetron in the prophylaxis of chemotherapy-induced delayed emesis. Anticancer Drugs 17(2):217-224 